\title{
Variability of the Currents' Vertical Structure in the Western Subtropical Atlantic and Meridian Heat Transport
}

\author{
A.B. Polonsky, S.B. Krasheninnikova \\ Marine Hydrophysical Institute, Russian Academy of Sciences, Sevastopol, \\ Russian Federation \\ e-mail: apolonsky5@mail.ru, svetlanabk@mail.ru
}

\begin{abstract}
Based on the WOCE (1988-1993) and RAPID (2004-2006) instrumental data, seasonal and synoptic variability of the currents' vertical structure in the western part of the Northern Subtropical Anticyclonic Circulation (NSAC) is analyzed and its contribution to formation of the meridian heat transport is defined. Maximum of the seasonal cycle annual harmonic is observed in summer-autumn and its minimum - in winter - spring. The secondary maximums are revealed in late spring and mid autumn. Approximately $40 \%$ of total variability of the currents' field falls on the superposition of the annual and semi-annual harmonics. Synoptic fluctuations with the periods 3-30 and 51-135 days condition a substantial portion (up to 50-60 \%) of hydrothermodynamic parameters' variability in the upper and intermediate layers. A portion of variability with the period 31-50 days does not exceed $10 \%$ of total dispersion. Influence of synoptic-scale vortex transports on the meridian thermohaline circulation and the associated meridian heat transport is most significant in the thermocline. With the seasonal variations taken into account, the synoptic vortices' contribution to the integral heat transport in the western part of NSAC (in vicinity of $26^{\circ} \mathrm{N}$ ) estimated by the RAPID instrumental data does not exceed $5 \%$.
\end{abstract}

Keywords: seasonal and synoptic variability of currents, meridian heat transport, RAPID and WOCE instrumental data, Subtropical Atlantic.

DOI: 10.22449/1573-160X-2015-3-35-49

(C) 2015, A.B. Polonsky, S.B. Krasheninnikova

(C) 2015, Physical Oceanography

\section{Introduction}

Meridian circulation (MC) and meridian heat transport (MHT) in the ocean play an important role in the climate system. The oceanic MHT conditions 2/3 of the total MHT in the ocean-atmosphere system at low latitudes, and its variability stipulates variations of the climate system parameters with the typical periods from $50-100$ to 1000 years [1, 2]. The ocean MC is composed mostly of thermohaline circulation conditioned by large-scale gradients of density, wind transport concentrated in the main thermocline, and drift currents mainly located in the upper Ekman layer [1, 3, and 4]. The opinion of many authors consists in the fact that an important role in MC formation is also played by the eddies which are conditioned by the velocity and temperature fluctuations on the synoptic scale [5 - 10]. Many papers are devoted to assessment of contribution of various physical mechanisms to the integral oceanic MHT. Some of them content that the heat transport associated with synoptic vortices is basic importantance in the total oceanic MHT [11 - 13], whereas the others assess its contribution as insignificant though recognize presence of considerable regional differences [14, 15].

The estimates of MHT resulted from application of long-term continuous series of the instrumental observations' data, are the most important. In contrast to occasional studies from the vessels, long-term monitoring of the zonal and meridian components of the current velocity, pressure and temperature at the buoy PHYSICAL OCEANOGRAPHY NO. 3 (2015) 
stations on various horizons permits to describe reliably the currents' vertical structure and to assess rather accurately their temporal variability in the chosen regions of the ocean. The data obtained in such a way provide the mass and heat transport estimates deprived of the uncertainties inherent to the transport indirect estimates obtained, for example, due to geostrophic relations. They are especially important on the considerable depths where the heat transfer barotropic component is of the same order as the baroclinic one, and the horizontal gradients in the density field are estimated with a considerable error [3, 5, 16, and 17].

The longest time series of the currents' direct measurements in the Subtropical Atlantic were done to the east off the Abaco Island in the Bahamas $\left(25-27^{\circ} \mathrm{N}\right)$. This region is unique due to the following reasons:

- it is located close to the MHT maximum in the North Atlantic [1];

- the highest number of hydrological sections were done just in this region [1, 3 and 14];

- MHT is conditioned there by the Florida and Antilles jet currents (FC and AC), in the rest of the pool the transport is directed oppositely [5, 13];

- the longest continuous observations of the Florida current were done on these latitudes [18 - 20].

Study of variability of mesoscale circulation and eddies in the Subtropical Atlantic using the data of long-term instrumental observations of currents is one of the basic tasks of numerous observational programs: MODE, POLYMODE, STACS, WATTS, ACCP, RAPID and WOCE [3 - 10, 16, 21 - 26]. These papers describe nature and typical spatial-temporal scales of the eddy formations' variability; contributions of the synoptic scale heat transfer to the MHT total variability in the northwestern NSAC. Significant effect of the heat transport by vortices in the western boundary layer of the Subtropical Atlantic is revealed.

Unfortunately, continuous instrumental observations do not cover the whole Subtropical Atlantic basin from one coast to another and from the surface to the bottom, but they provide reliable description of the currents' vertical structure and its variability on synoptic and intra-year scales in the western NSAC. This makes it possible to specify the contribution of heat transfers conditioned by the velocity and temperature correlations on the seasonal, synoptic and seasonal-synoptic scales to the integral MHT in the region where synoptic eddies are the most intense. Such a specification is just the purpose of the paper.

\section{Materials and method}

To estimate average monthly meridian mass (heat) transport in vicinity of $26^{\circ} \mathrm{N}$ in the western Subtropical Atlantic, the data on the current velocity meridian component $(V)$, temperature $(T)$ and pressure $(P)$ obtained from the autonomous buoy stations with the current acoustic meters were used. These data were obtained by the British Oceanographic Data Centre (British Oceanographic Data Centre) within the framework of the Rapid Climate Change Program (RAPID) at support of the National Environmental Research Council (National Environmental Research Council) by the projects RAPIDMOC (National Oceanography Centre, Southampton), 2004 - 2006, and MOCHA (Rosenstiel School of Marine and Atmospheric Science) [27] 2004, and also by the experiment World Ocean Circulation Experiment (WOCE) [28] 1988, 1990, 1992 and 1993 (Table 1). 
Table 1. Characteristics of the used instrumental data

\begin{tabular}{c|c|c|c|c}
\hline Program & $\begin{array}{c}\text { Number of } \\
\text { stations }\end{array}$ & $h_{\max }, \mathrm{M}$ & Year & Month number \\
\hline \multirow{3}{*}{ WOCE } & 3 & 455 & 1988 & $10^{\text {th }}$ \\
& 5 & 1497 & 1990 & 5 \\
& 5 & 5592 & 1992 & 2 \\
& 1 & 355 & 1993 & 9 \\
MOCHA & 7 & 4923 & 1993 & 10 \\
& 5 & 4853 & 2004 & $3-5$ \\
& 5 & 4129 & 2004 & $7-9$ \\
& 3 & 4111 & 2004 & 10 \\
RAPIDMOC & 2 & 4095 & 2004 & $10-12$ \\
& 5 & 4853 & 2005 & 1 \\
& 5 & 3108 & 2005 & $2-5$ \\
& 1 & 4000 & 2005,2006 & $5-12,1-3$ \\
& 1 & 555 & 2005,2006 & $5-12,1-3$ \\
& 1 & 4250 & 2005,2006 & $5-12,1-3$ \\
\hline
\end{tabular}

Discreteness of the data represented by the British Oceanographic Data Center is $12 \mathrm{~h}$. The deep-sea data on the current velocity meridian component are concentrated in the region $75-75.8^{\circ} \mathrm{W}$ in the $50-1400 \mathrm{~m}$ layer (the $1^{\text {st }}-12^{\text {th }}$ months) and up to the depth $\sim 5000 \mathrm{~m}$ (the $4^{\text {th }}$ and the $5^{\text {th }}$ months). A wider zone is covered by the observation data in the region of $\sim 72-77^{\circ} \mathrm{W}$ in the layer $\sim 100-$ $1400 \mathrm{~m}$ (the $2^{\text {nd }}$ and the $10^{\text {th }}$ months). The most long-term time series of $T$ and $V$ (up to 712 days) and the largest amount of the data on depth are observed in the region $26^{\circ} \mathrm{N}, 75-75.8^{\circ} \mathrm{W}$. Spatial-temporal distribution of the $V$ and $T$ data applied for calculating the mass (heat) transfer is shown in Fig. 1.
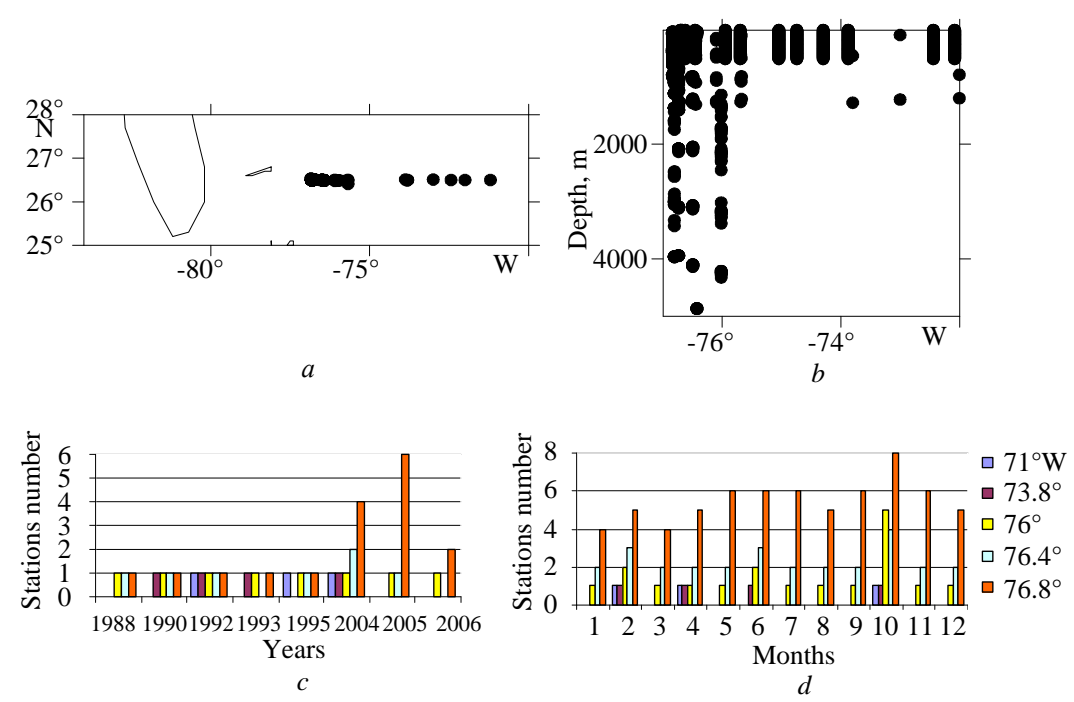

Fig. 1. Distribution of the velocity and temperature meridian component using the RAPID and WOCE instrumental data for 1988 - 2006 over horizontal $(a)$, vertical $(b)$, years $(c)$ and months $(d)$ PHYSICAL OCEANOGRAPHY NO. 3 (2015) 
The monthly average local meridian mass transports $(Q)$ in the region $26^{\circ} \mathrm{N}$, $72-77^{\circ} \mathrm{W}$ and $75-75.8{ }^{\circ} \mathrm{W}$ in the Subtropical Atlantic were calculated in a following way:

$$
\bar{Q}=\int_{h_{1}}^{h_{2}} \int_{L_{1}}^{L_{2}}(\bar{V}) d x d z,
$$

where $h_{1}, h_{2}$ are the upper and lower flow boundaries; $L_{1}, L_{2}$ are its western and eastern boundaries; the line from above denotes time averaging (for certain months of each year).

The monthly average local meridian heat transports $(H)$ were calculated by the formula

$$
\bar{H}=C_{P} \bar{\rho} \int_{h_{1}}^{h_{2}} \int_{L_{1}}^{L_{2}}(\bar{V} \bar{T}) d x d z,
$$

where $C_{P} \bar{\rho} \approx 4,18$ Дж/( $\left({ }^{\circ} \mathrm{C} \cdot \mathrm{cm}^{3}\right) ; \quad C_{P}$ is the seawater specific heat at constant pressure; $\rho$ is the seawater density.

Harmonic expansion of a series of $\bar{Q}$ and $\bar{H}$ monthly average values permitted to calculate the amplitude of the annual and semi-annual harmonics. Under the stipulation that velocity and temperature change on seasonal and synoptic scales, the annual average integral meridian heat transfer can be calculated by the following formula $[7,29]$ :

$$
\bar{H}=C_{P} \bar{\rho} \int_{0}^{h} \int_{L_{1}}^{h}(\overline{V T}+\overline{V^{\prime} T^{\prime}}+\overline{V^{\prime \prime} T^{\prime \prime}}+\underbrace{\overline{V^{\prime} T^{\prime \prime}}+\overline{V^{\prime \prime} T^{\prime}}}_{3}) d x d z,
$$

where $h$ is the ocean depth; the summands in the right part are of the following physical meaning: 1 - heat transfer conditioned by the medium meridian circulation; 2 - heat transfer connected with correlations of the fluctuations of the current velocity and temperature meridian components on the seasonal scale ( $V^{\prime}$, $T^{\prime}$ ); 3 - heat transfer related to correlations of the fluctuations of the current velocity and temperature meridian components on the synoptic scale ( $\left.V^{\prime \prime}, T^{\prime \prime}\right) ; 4-$ heat transfer associated with correlations of the fluctuations of the current velocity and temperature meridian components on the seasonal and synoptic scales. Longterm instrumental observations of the RAPID program permit to assess reliably summands 2, 3 and 4 of equation (3).

Synoptic characteristics of hydrothermodynamic fields were described and contribution of their variability to the total dispersion was assessed using the $R A P I D$ data. For this purpose, the $V$ and $T$ continuous series on each horizon at every station were subjected to spectral analysis. At that the assessments were done starting from the depth $\sim 250 \mathrm{~m}$. The spectra on the depths above $120 \mathrm{~m}$ were not analyzed since the seasonal thermocline zone is strongly affected by seasonal fluctuations. Due to the minimum in the oscillation spectrum that permits to separate the synoptic and mesoscale peaks, we managed to filter out reliably highfrequency fluctuations with the periods smaller than 3 days. Based on the spectra and the periods' diagrams, the typical periods of the hydrothermodynamic 38 PHYSICAL OCEANOGRAPHY NO. 3 (2015) 
parameters' synoptic variability were marked out. The initial series were processed by a band-pass rectangular filter for obtaining the $V^{\prime \prime}$ and $T^{\prime \prime}$ series. Then the contribution of the velocity and temperature fluctuations on the distinguished synoptic scales to the total dispersion of the original series was assessed. The obtained fluctuations were further used for evaluating heat transport by synoptic vortices in the region of $26^{\circ} \mathrm{N}$ in the Subtropical Atlantic. For this purpose, the $V^{\prime \prime}$ and $T^{\prime \prime}$ product was integrated over depth. After that the obtained integral was multiplied by the distance from America to Africa (about $5.5 \cdot 10^{6} \mathrm{~m}$ ); and that was the way of defining the searched heat transfer by the vortices estimated "from above" (as intensity of the synoptic processes in the western part of NSAC is much higher than in its central and eastern parts). Then the transport contribution to the integral MHT in vicinity of $26^{\circ} \mathrm{N}$ in the Subtropical Atlantic obtained earlier in [29] was assessed. This method of calculating heat transfer by the vortices is described in details in $[3,16]$.

The majority of synoptic eddies ( $\sim 90 \%)$ is concentrated in the western part of the Subtropical Atlantic, and not more than $10 \%$ of them fall on the rest of the basin $[13,26]$. Hence, having multiplied the integral $\int_{H} \overline{V^{\prime \prime} T "} d z$ by the western boundary layer width $\left(\sim 0.5 \cdot 10^{6} \mathrm{~m}\right)$, we can define the true heat transfer by the synoptic eddies approximately coinciding with the estimates resulted from the hydrological data [26, 29].

\section{Results}

Intra-annual variability of meridian mass (heat) transports in the Subtropical Atlantic. Based on the RAPID and WOCE data, the monthly average local mass (heat) transfers are obtained for winter (February) and autumn (October) in the region $26^{\circ} \mathrm{N}, 72-77^{\circ} \mathrm{W}$ of the Subtropical Atlantic. Analysis of Tabl. 2 shows that the basic heat/mass transfer to the north within these longitudes takes place in the upper $800 \mathrm{~m}$ layer. Below this depth, the transfer sign changes. The described circulation structure is confirmed by the results in [3, 5, 16, 17, 21, 24, 30 and 31]. Actually, in the upper $\sim 800 \mathrm{~m}$ layer the Antilles current directed to the north is located; below it, there is the Western Boundary Undercurrent (WBUC) directed to the south. A more detailed structure of the currents in the region under examination is seen in Fig. 2 which testifies to presence of intense sub-surface current with the core on the depth $400 \mathrm{~m}$. The maximum velocity in the core varies from season to season within the range $0.3-0.8 \mathrm{~m} / \mathrm{s}$. On the average, the annual AC discharge in the surface layer (above the marked core) is small since the currents there are alternating (the meridian velocity component varies in the range $-30 \ldots 30 \mathrm{~cm} / \mathrm{s}$ ). The core of the southward WBUC is located on the depth $1000-1200 \mathrm{~m}$; the current velocity in it changes in course of the whole year in the range $-10 \ldots-$ $30 \mathrm{~cm} / \mathrm{s}$. The exception is November for the station located in the region $26{ }^{\circ} \mathrm{N}$, $75.8^{\circ} \mathrm{W}$ (Fig. 2) where WBUC changed its direction to the north, but already in December it regained its southern direction. 

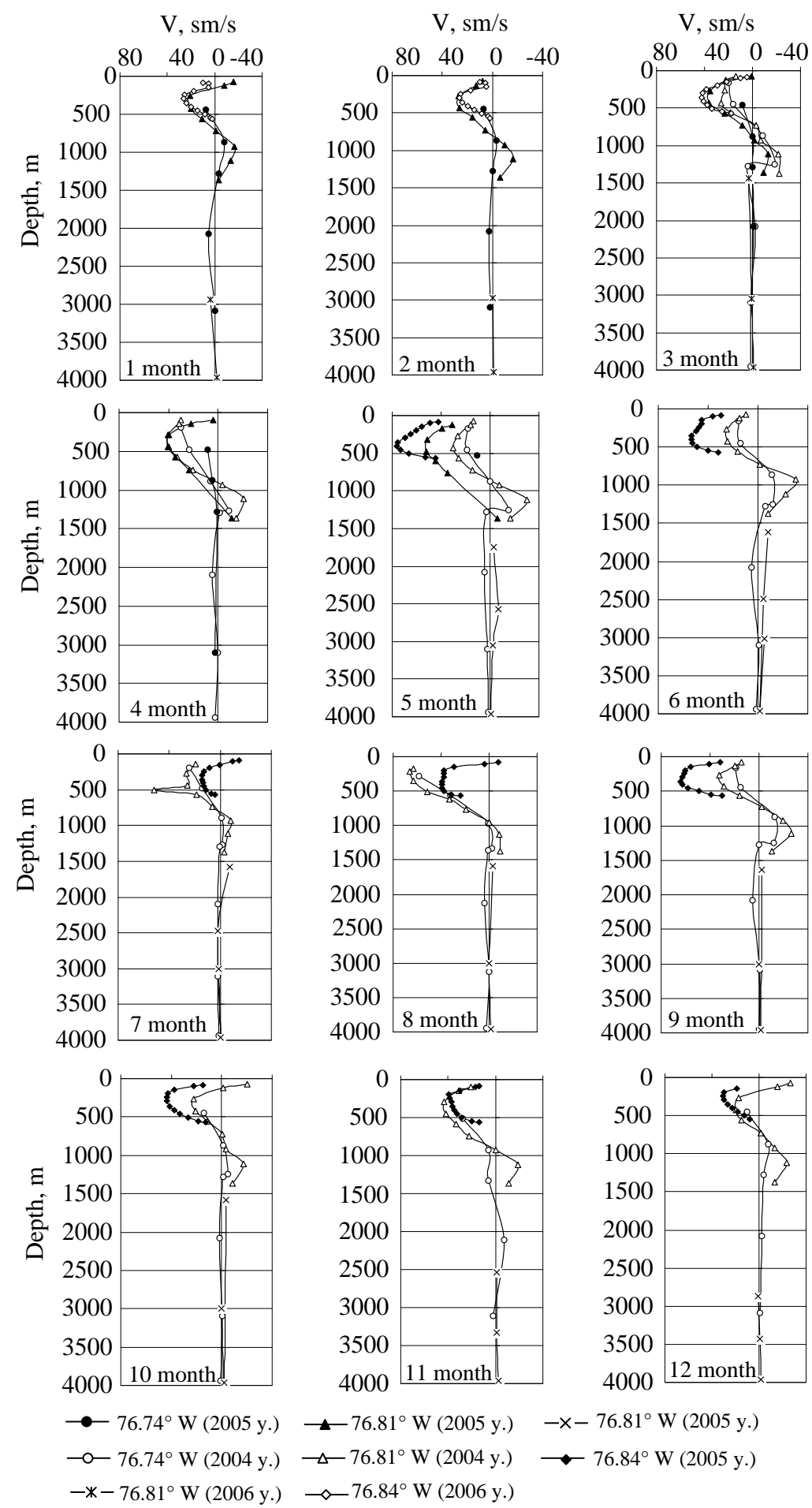

$-x-76.81^{\circ} \mathrm{W}(2005 \mathrm{y}$.)

$76.84^{\circ} \mathrm{W}(2005 \mathrm{y}$.

Fig. 2. Seasonal variability of vertical profiles of the velocity meridian component at the neighboring stations in the region $26^{\circ} \mathrm{N}, 75-75.8^{\circ} \mathrm{W}$ of the Subtropical Atlantic. 
Table 2. Monthly average mass $(Q)$ and heat $(H)$ transfers in the region $26{ }^{\circ} \mathrm{N}$, $72-77^{\circ} \mathrm{W}$ in the Subtropical Atlantic

\begin{tabular}{c|c|c|c|r}
\hline Month number & Years & Layers, $\mathrm{m}$ & $Q, \mathbf{S v}$ & $H, \mathbf{P W}$ \\
\hline \multirow{2}{*}{$2^{\text {nd }}$} & & $0-800$ & 8.5 & 0.54 \\
& \multirow{3}{*}{$1992-2006$} & $800-1000$ & -3.2 & -0.11 \\
& & $0-1000$ & 5.3 & 0.43 \\
& & $1000-1400$ & -9.4 & -0.24 \\
\multirow{3}{*}{$10^{\text {th }}$} & & $0-800$ & 13.5 & 1.01 \\
& \multirow{2}{*}{$1988-2006$} & $800-1000$ & -1.3 & -0.04 \\
& & $0-1000$ & 12.3 & 0.95 \\
& & $1000-1400$ & -4.5 & -0.14 \\
\hline
\end{tabular}

The authors of the present paper have found that the local mass (heat) transfer in the upper $800 \mathrm{~m}$ layer in the region $26^{\circ} \mathrm{N}, 72-77^{\circ} \mathrm{W}$ of the Subtropical Atlantic in February and October was $8.5 \mathrm{~Sv}$ (0.54 PW) and 13.5 Sv (1.01 PW), respectively, $\left(1 \mathrm{~Sv}=10^{6} \mathrm{~m}^{3} / \mathrm{s}, 1 \mathrm{PW}=10^{15} \mathrm{~W}\right)$. In other words, its value in this layer is lower in winter than in autumn, and in the layer $1000-1400 \mathrm{~m}$ the situation is opposite (Table 2.). The other months are not enough covered with the observational data, hence the transfers for these months were not calculated. The average multi-annual transport in the upper $1000 \mathrm{~m}$ layer is $\sim 8.8 \mathrm{~Sv}$ that, with the regard for the estimates' errors, agrees with the results in [5, 16 and 17] (Tabl. 3).

Table 3. Average multi-annual mass transfers $(Q, S v)$ in the region $26^{\circ} \mathrm{N}, 72-$ $77^{\circ} \mathrm{W}$ of the Subtropical Atlantic based on the data of different papers

\begin{tabular}{c|c|cc|c}
\hline \multirow{2}{*}{ Programs } & \multirow{2}{*}{ Years } & \multicolumn{2}{|c|}{ Layers, $\mathrm{m}$} & \multirow{2}{*}{ Paper } \\
\cline { 3 - 4 } & & $0-1000$ & $1000-5000$ & \\
\hline STACS-8 & 1987,1988 & $2.2 \pm 7.7$ & $-32.7 \pm 10.2$ & {$[5]$} \\
STACS-10 & $1988-1990$ & $7.0 \pm 8.5$ & $-27.5 \pm 17.2$ & {$[5]$} \\
WATTS & $1990-1992$ & $5.3 \pm 9.9$ & $-22.8 \pm 22.4$ & {$[5]$} \\
STACS, & & & & \\
WATTS & $1995-1997$ & $5.0 \pm 3.0$ & $-25.0 \pm 23.0$ & {$[17]$} \\
RAPID & 2004,2005 & 5.0 & -25.5 & {$[16]$} \\
RAPID, WOCE & $1988-2006$ & 8.8 & - & Present paper \\
\hline
\end{tabular}

In the present paper the WBUC discharge was not assessed due to lack of the data for the layers below $1000 \mathrm{~m}$. Model simulations in [5, 16 and 17] provided a foundation for obtaining the WBUC discharge values on the depth $800 \mathrm{n}-4800 \mathrm{~m}$ which vary from $-22.8 \pm 22.4$ to $-32.7 \pm 10.2 \mathrm{~Sv}$ (Tabl. 3). The transfer of the southward WBUC can be considered barotropic.

The intra-year heat (mass) transport was not also assessed in this region as it was already done in $[5,22]$. In [5] within the intra-year cycle of the local mass transport, the maximums and minimums were distinguished in summer and winter, 
and in the mid spring and autumn, respectively, based on the buoys' data (programs STACS-8, STACS-10, WATTS). It is shown in [22] that transport achieves its maximum in winter and its minimum - in autumn; presence of the secondary peak in summer and minimum in spring is also noted. In [5] this feature of the intra-year cycle is associated with the barotropic response to a remote or local wind effect. It is also shown that synoptic eddies moving to the west at the velocity $4 \mathrm{~cm} / \mathrm{s}$ dominate in the transfers' variability on the scales smaller than the semi-annual one. The corresponding spatial-temporal scale is characterized by the wavelength $335 \mathrm{~km}$ and the typical periods $70-100$ days. In [16] it is explained by water recirculation in the western NSAC and by existence of the local eddy formations to the northeast off the Abaco Island that is confirmed by the existing notion on volatility of the Antilles current in the upper $1000 \mathrm{~m}$ layer [30, 31].

Fig. 3 shows intra-annual variability of the local heat (mass) transfer in the region $26^{\circ} \mathrm{N}, 75-75.8^{\circ} \mathrm{W}$ of the Subtropical Atlantic in the $800 \mathrm{~m}$ layer (i. e. in the Antilles current). Maximum of the annual harmonic is observed in summer autumn and its minimum - in winter - spring. This fact is confirmed by the estimates obtained in [17]. Note that in addition to the primary maximum in August, the secondary peaks in May and November are well pronounced. Analysis of the individual profiles of the velocity meridian component also confirms presence of the marked maximums in late spring and autumn (figure is omitted). The AC intra-annual cycle agrees very well with its descriptions in [10, 17 and 30]. Note that there are no extremums in May and November in the FC average multiyear seasonal cycle. The fact that the Antilles and Florida currents' discharges do not correlated with each other on the intra-annual scale is also confirmed by the data in [17].
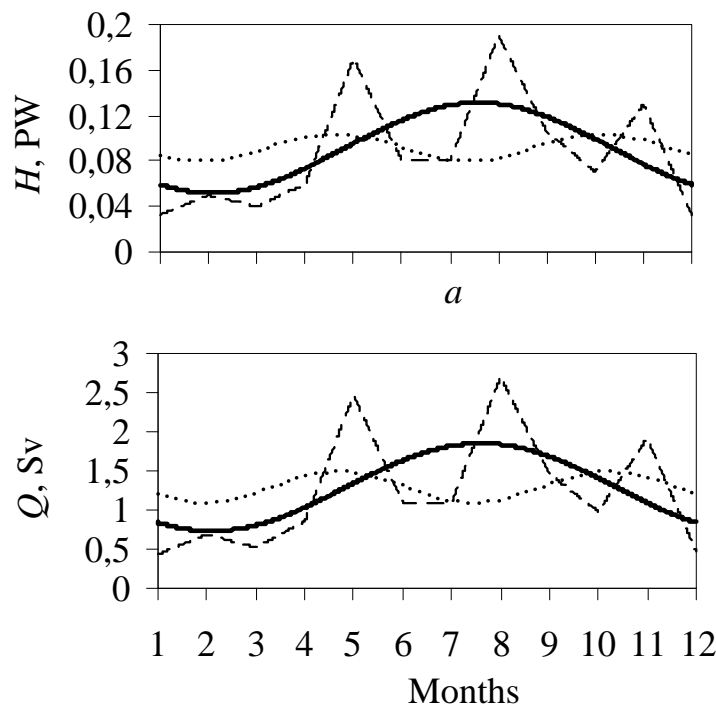

$b$

Fig. 3. Intra-annual variability of the local heat $(a)$ and mass $(b)$ transfer in the region $26{ }^{\circ} \mathrm{N}, 75-$ $75.8^{\circ} \mathrm{W}$ of the Subtropical Atlantic: the solid line denotes annual harmonic, the hatch line - initial series and the dotted line - semi-annual harmonic 
The dispersion analysis performed in the present paper showed that $~ 30-$ $40 \%$ of the initial series dispersion fell on the annual harmonic in variability of the mass (heat) transfers in the region $26^{\circ} \mathrm{N}, 75-75.8{ }^{\circ} \mathrm{W}$ and $\sim 5-10 \%-$ on the semi-annual one. Thus, only $40 \%$ of the intra-annual cycle of the meridian heat (mass) transfer in $2004-2006$ is described by the annual and semi-annual harmonics' superposition. It is also shown in $[18,20]$ that contribution of the first two harmonics to the total dispersion of the FC discharge in vicinity of $27^{\circ} \mathrm{N}$ can be smaller than that of the higher order harmonics.

It follows from the obtained results and published papers that in the region of $26^{\circ} \mathrm{N}$ the harmonics' contribution is more significant that testifies to the important role of the synoptic vortices in the regional dynamics [10, 17, 23, 25 and 30].

Let us analyze the vortex formations conditioned by considerable fluctuations of the velocity and temperature meridian component on the synoptic scales which are mainly related to the baroclinic-barotropic instability of the currents' system in the western part of the Subtropical Atlantic [13, 16 and 30] and to the Rossby waves of the first baroclinic mode generated by moving synoptic vortices [26, $32-$ 34].

Synoptic variability of hydrothermodynamic parameters and estimation of contribution of the dispersion conditioned by these fluctuations to the total dispersion. It is known that the vortices' position and their form change with time. Therefore during various time periods the buoy stations can be affected by different parts of the vortex formations and by the direction of their movement. It is well reflected in the average diurnal series of the current velocity and temperature meridian component (Fig. 4). On the average the amplitudes of the $V$ and $T$ synoptic variations are $10-20 \mathrm{~cm} / \mathrm{s}$ and $0.7-1^{\circ} \mathrm{C}$ in the upper ( 800 $\mathrm{m}$ ) layer, 5 $7 \mathrm{~cm} / \mathrm{s}$ and less than $0.5^{\circ} \mathrm{C}$ - in the intermediate $(1000-2000 \mathrm{~m})$ layer, $2-5 \mathrm{~cm} / \mathrm{s}$ and less than $0.2{ }^{\circ} \mathrm{C}$ - in the deep-sea $(2500-5000 \mathrm{~m})$ layer. Analysis of Fig. 4 shows that the maximums and minimums in the filtered series (the period is 51 135 days) do not always coincide over depth. The coincidence remains more or less in the layer $730-1100 \mathrm{~m}$.

It is well known that synoptic eddies in the ocean are divided into the cyclonic and anticyclonic ones which are characterized by cold and warm cores in the vortices' central parts and by warmer and colder water on the vortices' peripheries, respectively. At that the vortices of frontal origin are located to the right (cyclonic) and to the left (anticyclonic) of the main stream [35]. The annual average numbers of cyclonic and anticyclonic formations coincide -5 vortices of each sign (Fig. 4.). The most intensive cyclonic vortices are formed in summer (June and July) and in autumn (October).

Tabl. 4 represents the assessments of the dispersion contributions conditioned by the hydrothermodynamic parameters' variability on the synoptic scales to the total dispersion. They show that the $V^{\prime \prime}$ and $T^{\prime \prime}$ fluctuations with the periods $3-30$ and $51-135$ days stipulate a significant part (up to $50-60 \%$ ) of total variability in the upper $(800 \mathrm{~m})$ and the intermediate layers. It is confirmed by the results in [5, 30 and 33] where similar characteristics of baroclinic-unstable waves propagating to the west were found.

In the deep-sea layer, the largest contribution ( $\sim 80 \%)$ is done by the oscillations with the period $3-30$ days. Analysis of the current velocities' series in PHYSICAL OCEANOGRAPHY NO. 3 (2015) 
[34] shows that the fluctuations with the periods $\sim 50$ and $\sim 30$ days are predominant in the variability on all the analyzed (three) WBUC levels (1500, 1800 and $2100 \mathrm{~m}$ ). Note that on the depths exceeding $2500 \mathrm{~m}$, the $V$ and $T$ fluctuations are small (similar to measurement inaccuracy).
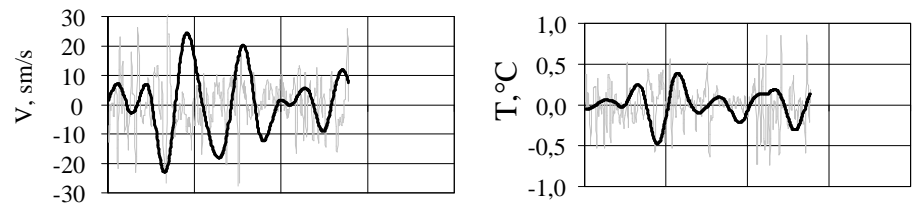

$262 \mathrm{~m}$
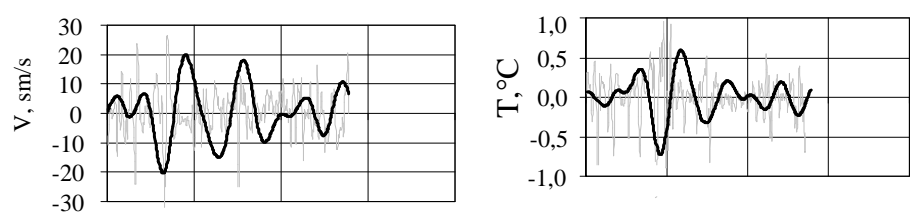

$430 \mathrm{~m}$
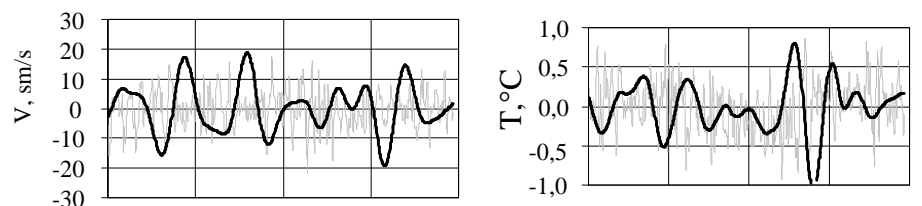

$730 \mathrm{~m}$
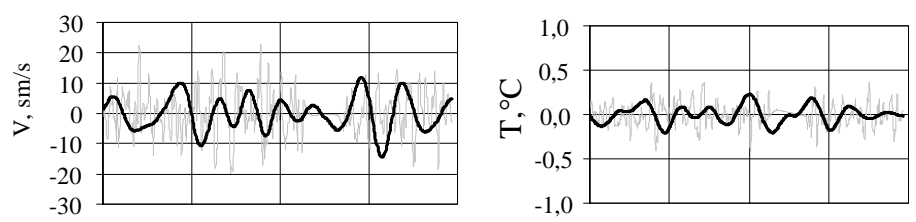

$1100 \mathrm{~m}$
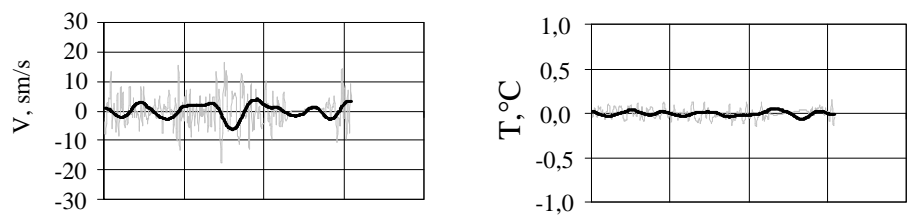

$2100 \mathrm{~m}$
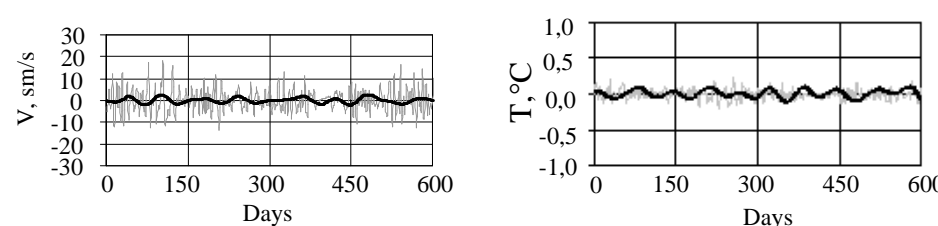

$3100 \mathrm{~m}$

Fig. 4. Series of hydrothermodynamic parameters in the region $26^{\circ} \mathrm{N}, 75.8^{\circ} \mathrm{W}$ of the Subtropical Atlantic (March, 2004 - November, 2005) on different horizons processed the band-pass filter with the periods 3 - 30 days (gray lines) and 51 - 135 days (black lines) after the initial series detrending

Thus, confirmed are the results of the earlier papers [16, 17 and 22] according to which influence of the synoptic scale vortex transports upon the MC (and the associated MHT) is the most significant in the thermocline (up to the depths 1000 $2000 \mathrm{~m}$ ) in the western Subtropical Atlantic since just there the $V$ and $T$ maximum 
variations are observed on these scales. The vortex heat transfers below the thermocline are much weaker. They accumulate only $5 \%$ of the average heat transfer by the vortices [22].

Table 4. Dispersion contribution (\%) on different time scales to the total dispersion

\begin{tabular}{|c|c|c|c|c|c|c|c|}
\hline \multirow{3}{*}{${ }^{\circ} \mathrm{W}$} & \multirow{3}{*}{ Depth, m } & \multicolumn{3}{|c|}{$V^{\prime \prime}$} & \multicolumn{3}{|c|}{$T^{\prime \prime}$} \\
\hline & & \multicolumn{6}{|c|}{ Period, day } \\
\hline & & $3-30$ & $31-50$ & $51-135$ & $3-30$ & $31-50$ & $51-135$ \\
\hline \multirow{5}{*}{75.74} & 250 & 25 & 5 & 35 & 30 & 4 & 19 \\
\hline & 430 & 24 & 5 & $\underline{33}$ & $\underline{32}$ & 5 & 23 \\
\hline & 730 & 19 & 7 & $\underline{35}$ & $\underline{30}$ & 2 & 20 \\
\hline & 1100 & $\underline{34}$ & 11 & 15 & $\underline{22}$ & 9 & 17 \\
\hline & 1370 & 34 & 10 & 11 & 22 & 13 & 18 \\
\hline \multirow{3}{*}{75.81} & 2089 & $\underline{42}$ & 3 & 9 & $\underline{47}$ & 15 & 11 \\
\hline & 3092 & 82 & 4 & 4 & $\underline{24}$ & 4 & 18 \\
\hline & 3940 & 34 & 3 & 8 & 30 & 2 & 4 \\
\hline
\end{tabular}

Note. The underlined values are the largest contributions to the total variability.

Heat transfer by synoptic eddies and its contribution to the average multi-year MHT. Integral heat transfer by synoptic vortices in the Subtropical Atlantic with a typical period 3 - 30 days estimated "from above" in the present paper is $0.25 \mathrm{PW}$ (Tabl. 5). The analogous order value of such transfer was obtained for the regions of $40^{\circ} \mathrm{N}(0.1 \mathrm{PW})$ and $15^{\circ} \mathrm{N}(-0.2 \mathrm{PW})$ in [11]. Consequently, heat transfer by the vortices of this scale can reach $10-20 \%$ of the integral MHT (1.33 PW) estimated based on hydrological data on the zonal sections in [29]. Of course, this estimate is evidently overstated as it was defined for the MHT maximum value integrated over the depth of the western boundary layer where intensity of synoptic fluctuations of the hydrothermodynamic fields is the highest. At the other stations, the smaller values were revealed; at that the sign of $\left(V^{\prime \prime} T^{\prime \prime}\right)$ may be different. Our data shows that at the majority of the stations $\left(V^{\prime \prime} T^{\prime \prime}\right)$ does not change its sign in the thermocline; however it can change it in the upper layer and below the thermocline. The result is that integration of $\left(V^{\prime \prime} T^{\prime \prime}\right)$ over the whole basin width for all the seasons and over the whole thermocline provides the estimate of the heat transfer by vortices and, hence, its contribution to the integral MHT that should be approximately by an order smaller than the obtained one. This conclusion is confirmed by the results in $[14,15]$ according to which the hydrological data shows that the discussed contribution of the vortex transfers is $~ 1 \%$. The paper [13] shows that, according to the RAPID instrumental data, the transfer can vary in the range 0.02 ... $0.22 \mathrm{PW}$. 
Table 5. Heat transfer by synoptic vortices $\left(\overline{H^{\prime \prime}}\right)$ and its contribution to the integral MHT $(\bar{H})$ in the region of $26^{\circ} \mathrm{N}$ of the Subtropical Atlantic

\begin{tabular}{c|c|c|c|c}
\hline \multirow{2}{*}{ MHT, PW } & $\begin{array}{c}\text { Estimate “from above” of the } \\
\text { vortex MHT from one coast } \\
\text { to another }\end{array}$ & $\begin{array}{c}\text { Estimate of the vortex MHT in the } \\
\text { western boundary layer }\end{array}$ \\
\cline { 2 - 5 } & \multicolumn{4}{|c}{ Period, day } \\
\cline { 2 - 5 } & $3-30$ & $31-135$ & $3-30$ & $31-135$ \\
\hline $\bar{H}$ ", PW & 0.25 & 0.08 & 0.02 & 0.01 \\
$\bar{H}, \mathrm{PW}$ & 1.33 & 1.33 & 1.33 & 1.33 \\
Contribution, \% & 18.9 & 6.2 & 1.7 & 0.6 \\
\hline
\end{tabular}

In the present paper the authors have obtain the estimate of heat transfer by synoptic vortices just separately for the western part of the Subtropical Atlantic. It was found to be $0.02 \mathrm{PW}$. In [36] the vortex transfer simulated by the eddyresolving models is close to this value. The estimates of heat transfer in the Subtropical Atlantic resulted from the current meters [22, 37 and 38] are smaller than $0.05 \mathrm{PW}$.

Thus, the contribution of the eddy heat transfers assessed by the RAPID instrumental data to the average integral MHT is small and constitutes $\sim 1 \%$, that is completely consistent with the results obtained in [13-15].

Based on the RAPID instrumental data, at one of the stations (summand 2 in (3)) the heat transfer conditioned by the $V$ and $T$ seasonal fluctuations constitutes $0.03 \mathrm{PW}$. Its contribution to the integral MHT in vicinity of $26^{\circ} \mathrm{N}$ is $\sim 3 \%$ that is in agreement with the results in [7]. It is shown in [7] that the contribution of the correlations both of temperature seasonal fluctuations, and the drift and gradient currents' velocity to the average annual MHT is small and makes not more than $10 \%$ in the Equatorial-Tropical Atlantic, and in the Subtropical Atlantic $\left(\sim 26{ }^{\circ} \mathrm{N}\right)$ it is considerably smaller.

The heat transfer estimates conditioned by the velocity and temperature seasonal-synoptic fluctuations (summands 4 in (3)) and resulted from the RAPID instrumental data have shown that at calculating the integral heat transfer they can be neglected as their total contribution is less than $0.1 \%$.

\section{Conclusion}

Seasonal and synoptic variability of the currents' vertical structure in the western part of the Northern Subtropical Anticyclonic Circulation is described based on the available data of continuous instrumental observations WOCE (1988 1993) and RAPID (2004 - 2006).

Having been analyzed the intra-annual cycle of the local mass (heat) meridian transfer in the region $\sim 26^{\circ} \mathrm{N}, 75-75.8^{\circ} \mathrm{W}$ shows that maximum of its annual harmonic is observed in summer-autumn and its minimum - in winter-spring. At the same time presence of the secondary maximums in late spring and mid autumn is noted. Approximately $40 \%$ of the initial series dispersion falls on variability of 
the annual and semi-annual harmonics of the intra-annual cycle of the local meridian heat (mass) transfer.

The average values of the amplitudes of the $V$ and $T$ synoptic variations are specified: for the upper $(\sim 800 \mathrm{~m})$ layer they are $10-20 \mathrm{~cm} / \mathrm{s}$ and $0.7-1{ }^{\circ} \mathrm{C}$, for the intermediate $(1000-2000 \mathrm{~m})$ layer $-5-7 \mathrm{~cm} / \mathrm{s}$ and less than $0.5^{\circ} \mathrm{C}$, for the deep-sea $(2500-5000 \mathrm{~m})$ layer $-2-5 \mathrm{~cm} / \mathrm{s}$ and less than $0.2^{\circ} \mathrm{C}$.

Synoptic fluctuations with the periods $3-30$ and $51-135$ days stipulate up to $50-60 \%$ of the total variability of hydrothermodynamic parameters in the upper 2000 m layer. Contribution of the intermediate period (31 - 50 days) variability to the total dispersion does not exceed $10 \%$.

It is revealed that basic contribution to the heat transfer in the region of $26^{\circ} \mathrm{N}$ in the Subtropical Atlantic is done by the quasi-stationary meridian circulation ( $95 \%$ ). Approximately $5 \%$ of the integral MHT is related to the non-stationary effects. Contribution of the vortex heat transfer in the western boundary layer of the Subtropical Atlantic can achieve $10 \%$ of the integral MHT.

Acknowledgements. The research was supported by the RFFR grant (15-0502019A) "Meridian heat transfer in the Tropical and Subtropical Atlantic: the role of different mechanisms and low-frequency variability."

\section{REFERENCES}

1. Polonsky, A.B., 2008, "Rol' okeana $v$ izmeneniyah klimata [The role of the ocean in climate]”, Kiev, Naukova Dumka, 184 p. (in Russian)

2. Hastenrath S., 1980, “Heat budget of ocean”, J. Phys. Oceanogr., vol. 10, no. 2, pp. 159-170.

3. Bryden, H.L., Johns, W.E. \& Saunders, P.M., 2005, “Deep Western Boundary Current east off Abaco: Mean structure and transport”, J. Mar. Res., vol. 53, no. 1, pp. 35-57.

4. Cunningham, S.A., Kanzow, T. \& Rayner, D., 2007, "Temporal variability of the Atlantic meridional overturning circulation at $25.5^{\circ} \mathrm{N}$ ”, Science, vol. 317, pp. 935-938.

5. $\quad$ Lee T.N., Johns, W.E. \& Zantop, R.J. [et al.], 1996, "Moored observations of Western Boundary Current variability and termohaline circulation at $26.5^{\circ} \mathrm{N}$ in the Subtropical North Atlantic”, J. Phys. Oceanogr., vol. 26, pp. 962-983.

6. Baehr, J., Hirschi, J. \& Beismann, J.-O. [et al.], 2004, "Monitoring the meridional overturning circulation in the North Atlantic: A model-based array design study”, J. Mar. Res., vol. 62, pp. 283-312.

7. “Gidrofizika Tropicheskoy Atlantiki, [Hydrophysics Tropical Atlantic] ”, 1993, pp. 35-48 (in Russian).

8. Kanzow, T., Cunningham, S.A. \& Johns, W.E. [et al.], 2010, "Seasonal variability of the Atlantic meridional overturning circulation at $26.5^{\circ} \mathrm{N}$ ”, J. Climate, vol. 23, pp. 5678-5698.

9. Michael, A., Scott, A., 1997, "Surface flux variability over the North Pacific and North Atlantic oceans”, J. Climate, vol. 10, pp. 2963-2978.

10. Polonsky, A.B., 1989, "Gorizontalno-odnorodniy deyatelniy sloy oceana i ego modelirovanie [Horizontal heterogeneous active layer of the ocean and its modeling]", Obninsk, RIHMIWDC, 233 p.

11. Jayne, S.R., Marotzke, J., 2002, “The oceanic eddy heat transport”, J. Phys. Oceanogr., vol. 32, pp. 3328-3345.

12. Lozier, M.S., 2010, “Deconstructing the Conveyor Belt”, Science, vol. 238, pp. 1507-1511.

13. Johns, W.E., Baringer, M.O. \& Beal, L.M. [et al.], 2011, “Continuous, array-based estimates of Atlantic ocean heat transport at $26.5^{\circ} \mathrm{N}$ ”, J. Climate, vol. 24, pp. 2429-2449. 
14. Hall, M.M., Bryden, H.L., 1982, "Direct estimates and mechanisms of ocean heat transport", Deep-Sea Res., vol. 29, no. 3A, pp. 339-359.

15. Polonsky, A.B., Krasheninnikova, S.B., 2006, “Ozenka okeanicheskogo meridionalnogo perenosa tepla $v$ Subtropicheskoy Atlantike [Estimate of oceanic meridional heat transport in the Subtropical Atlantic] ”, Morskoy gidrofizicheskiy zhurnal, no. 1, pp. 3-15 (in Russian).

16. Johns, W.E., Beal, L.M. \& Baringer, M.O. [et al.], 2008, "Variability of Shallow and Deep Western Boundary Currents off the Bahamas during 2004-05: Results from the $26^{\circ} \mathrm{N}$ RAPID-MOC array”, J. Phys. Oceanogr., vol. 38, no. 4, pp. 605-622.

17. Meinen, C.S., Garzoli, S.L. \& Johns, W.E. [et al.], 2004, "Transport variability of the Deep Western Boundary Current and the Antilles Current off Abaco Island, Bahamas”, Deep-Sea Res., P.I, vol. 51, no. 1, pp. 1397-1415.

18. Meinen, C.S., Baringer, M.O. \& Garcia, R.F., 2010, "Florida Current transport variability: An analysis of annual and longer period signals”, Deep-Sea Res., P.I, vol. 57, pp. 835-846.

19. Dzhiganshin, G.F., Krasheninnikova, S.B. \& Polonsky, A.B., 2009, "Nizkochastotnaya izmenchivost' Floridskogo techeniya [Low-frequency variability of the Florida current]", Ekologicheskaya bezopasnosnost' pribreznoy i shelfovoy zon i kompleksnoe ispolzovanie resursov shelfa, vol. 19, pp. 415-422 (in Russian).

20. Karlin, L.N., Malinin, V.N. \& Gordeeva, S.M., 2013, "The variability of hydro-physical characteristics in the Gulf Stream”, Oceanology, vol. 53, no. 4, pp. 454-462.

21. Fu, L.-L., Keffer, T. \& Niller, P.P. [et al.], 1982, "Observations of mesoscale variability in the western North Atlantic: A comparative study”, J. Mar. Res., vol. 40, no. 3, pp. 809-849.

22. Fillenbaum, E.R., Lee, T.N. \& Johns, W.E. [et al.], 1997, "Meridional heat transport variability at $26.5^{\circ} \mathrm{N}$ in the North Atlantic”, J. Phys. Oceanogr., vol. 27, pp. 153-174.

23. Freeland, H.J., Rhines, P.B. \& Rossby, H.T., 1997, "Statistical observations of the trajectories of neutrally buoyant floats in the North Atlantic”, J. Mar. Res., vol. 33, pp. 383-404.

24. Olson, D.B., Schott, F.A. \& Zantopp, R.J. [et al.], 1984, "The mean circulation east of the Bahamas as determined from a recent measurement program and historical XBT data”, $J$. Phys. Oceanogr., vol. 14, pp. 1470-1487.

25. Riser, S.C., Rossby, H.T., 1983, “Quasi-lagrangian structure and variability of the subtropical western North Atlantic circulation”, J. Mar. Res., vol. 41, pp. 127-162.

26. Korotaev, G.K., 1988, “Teoreticheskoe modelirovanie sinopticheskoy izmenchivosti okeana [Theoretical modeling of synoptic ocean variability]”, Kiev, Naukova Dumka, 160 p. (in Russian).

27. Metadata Report for L: Iusers\bodc|requests\rn88004\rn88004.

28. WOCE Global Data. Version 3.0, 2002. WOCE International Project Office // WOCE Report No.180/02. - Southampton, UK.

29. Polonsky, A.B., Krasheninnikova, S.B., 2007, "Meridionalniy perenos tepla $v$ Severnoy Atlantike i tendentsii ego izmeneniy vo vtoroy polovine $X X$ veka [Meridional heat transport in the North Atlantic and its tendences in the second part of the XX century]”, Morskoy gidrofisicheskiy zhurnal, no. 1, pp. 45-59 (in Russian).

30. Gunn, J.T., Watt, D.R., 1982, "On the currents and water masses north of the Antilles/Bahamas Arc”, J. Mar. Res., vol. 40, pp. 1-48.

31. Wüst, G., 1924, “Florida and Antillean strom” Berlin U., Institut für Meereskunde, Veröff. N. F., A. Geogr.-naturwiss, Reihe, Heft 12., 48 p.

32. Chepurin, G.A., 1985, "Vliyanie vertikal'nogo sdviga na kharakteristiki skorosti srednego potoka $v$ sinipticheskoy izmenchivosti okeana [Influence of the vertical shift in the average flow velocity characteristics of synoptic variability in the ocean]”, Tezisy dissert., Sevastopol, MGI AN USSR, 122 p. (in Russian)

33. Halliwell, G.R., Peng, J.J. \& Olson, D.B., 1994, "Stability of the Sargasso Sea subtropical frontal zone”, J. Phys. Oceanogr., vol. 24, pp. 1166-1183.

34. Fischer, J., Schott, F.A., 2012, "Seasonal transport variability of the Deep Western Boundary Current in the equatorial Atlantic”, J. Geophys. Res., vol. 102, pp. 27751-27769. 
35. Nelepo, B.A., Bulgakov, N.P.\& Timchenko, I.E. [et al.], 1980, "Sinopticheskie vikhri v okeane [Synoptic eddies in the ocean]”, Kiev: Nauka, Mnenie, 288 p. (in Russian).

36. Stammer, D., 1998, “On eddy characteristics, eddy transports, and mean flow properties", $J$. Phys. Oceanogr., vol. 28, pp. 727-739.

37. Leaman, K.D., Molinari, R.L. \& Vertes, P.S., 1987, "Structure and variability of the Florida Current at $27^{\circ} \mathrm{N}$ : April 1982 - July 1984”, J. Phys. Oceanogr., vol. 17, pp. 565-583.

38. Wunsch, C., 1999, “Where do ocean eddy heat fluxes matter?”, J. Geophys. Res., vol. 104, pp. 13235-13249. 